\title{
Synthesis of a bifunctional 1,2,3,4-tetrahydroquinoline derivative: 4,4-(1,4-phenylene)di(1,2,3,4-tetrahydrobenzo[f]quinolin-2-ol)
}

\author{
Rimgaile Degutyte, ${ }^{a, b}$ Jolanta Stumbraite, ${ }^{a}$ and Vytautas Getautis ${ }^{\mathrm{a}}$ * \\ ${ }^{a}$ Department of Organic Chemistry, Kaunas University of Technology, Radvilenu pl. 19, LT- \\ 50279 Kaunas, Lithuania \\ ${ }^{b}$ Faculty of Pharmacy, Kaunas University of Medicine, A. Mickeviciaus g. 9, \\ LT-44307 Kaunas, Lithuania \\ E-mail: vgetaut@ktu.lt
}

\begin{abstract}
$N, N `$-di(3-chloro-2-hydroxypropyl)- $N, N `$-di(2-naphthyl)-1,4-diaminobenzene upon intramolecular cyclization gives bis-1,2,3,4-tetrahydroquinoline derivative - 4,4-(1,4phenylene)di(1,2,3,4-tetrahydrobenzo[f]quinolin-2-ol).
\end{abstract}

Keywords: 1,2,3,4-Tetrahydroquinoline, epichlorohydrin, regioselective cyclization, ditetrahydrobenzo[f]quinolin-2-ol

\section{Introduction}

The chemistry of 1,2,3,4-tetrahydroquinolines is of interest among many investigations during recent years. The growing interest in them can be explained by their biological activities. Substituted tetrahydroquinolines are the core structures in many important pharmacological agents, ${ }^{1-5}$ many relatively simple synthetic $1,2,3,4$-tetrahydroquinolines are already in use or have been tested as potential drugs. ${ }^{6-8}$ Besides pharmaceutical applications, tetrahydroquinoline derivatives are useful as pesticides, ${ }^{9}$ antioxidants, ${ }^{10}$ corrosion inhibitors, ${ }^{11}$ and active components of various dyes. ${ }^{12}$ In addition, they also have found application in modern recording technologies. ${ }^{13,14}$ Consequently, synthesis methodologies for preparing tetrahydroquinoline derivatives have attracted considerable interest and several methods offering good results have been reported. ${ }^{15}$ The nature, number, and relative location of the substituents are the key parameters to consider before choosing a method. Until now, much attention has been paid to the development of synthesis of monofunctional 1,2,3,4-tetrahydroquinolines, but the bifunctional 1,2,3,4-tetrahydroquinoline derivatives have been seldom investigated. 


\section{Results and Discussion}

Recently, during our ongoing research program on the study of interaction products of epichlorohydrin with aromatic amines, we have found that 3-hydroxy-1-phenyl-1,2,3,4tetrahydroquinoline can be prepared from $N$-2,3-epoxypropyl derivative of diphenylamine, or directly from diphenylamine by heating it with excess epichlorohydrin. ${ }^{16-18}$ The formation of tetrahydroquinoline core from diphenylamine has been proved to occur via the intermediate $\mathrm{N}$ (3-chloro-2-hydroxypropyl)diphenylamine. ${ }^{19,20}$ This prompted us to apply these procedures in developing the synthesis of a bifunctional condensed tetrahydroquinoline derivative from $N, N^{`}$ di(3-chloro-2-hydroxypropyl)- $N, N$-di(2-naphthyl)-1,4-diaminobenzene (3). We expected electrophilic attack of the aliphatic side chains in $\mathbf{2}$ and $\mathbf{3}$ on the $\boldsymbol{o}$-position of the phenyl or naphthyl moieties, thus leading to intramolecular cyclization to two condensed tetrahydroquinoline rings hereby giving compounds $\mathbf{4}$ or $\mathbf{5}$ (Scheme 1).

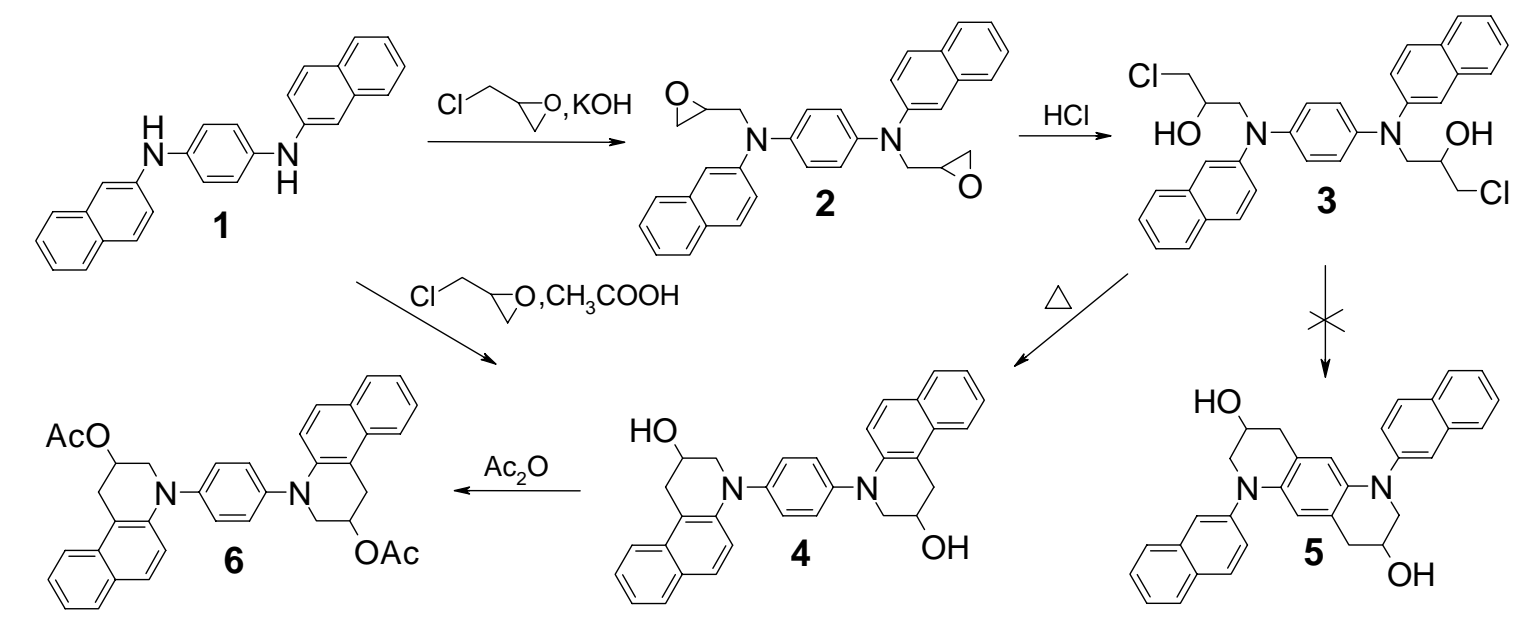

\section{Scheme 1}

First, the reaction of $N, N^{\prime}$-di(2-naphthyl)-1,4-diaminobenzene with epichlorohydrin in the presence of $\mathrm{KOH}$ at $25-30{ }^{\circ} \mathrm{C}$ was carried out and 2 was obtained in $62 \%$ yield. It should be noted that all our attempts to isolate the desired tetrahydroquinoline derivative under the reaction conditions described in Ref. ${ }^{16}$ were unsuccessful. Then, compound $\mathbf{3}$ was easily obtained by the action of dilute hydrochloric acid on the diepoxy compound 2. The following cyclization of 3 was performed in refluxing 1-hexanol for 7 hours to give a final product. TLC monitoring during the course of the reaction showed two products, one of them (presumably monofunctional) gradually blending in favour of the other (bifunctional). It was found that the reaction time could be reduced up to 3 hours by changing the reaction solvent to more polar $o$-dichlorobenzene. The product crystallized out after the solvents were removed. Since we could expect two possible tetrahydroquinoline products (4 or 5), depending on the direction of cyclization, the structure was resolved from the spectral data. 
Thus, the mass spectrum and elemental analysis data are consistent with both probable structures $\mathbf{4}$ or $\mathbf{5}$. A consideration of two-dimensional ${ }^{1} \mathrm{H}-{ }^{1} \mathrm{H}$ COSY data facilitated assignment of resonances to appropriate heteroaromatic protons. In the ${ }^{1} \mathrm{H}$ NMR spectrum (DMSO- $d_{6}$ ) of the isolated product signals are present which can be assumed to the five non-equivalent protons of the formed tetrahydroquinoline ring. The resonances of $\mathrm{ArCH}_{2}$ protons appeared as two doublets of doublets at $2.91 \mathrm{ppm}$ and $3.34 \mathrm{ppm}$ with $J_{\mathrm{AB}}=16.6, J_{\mathrm{AX}}=5.4$ and $J_{\mathrm{BX}}=7.4 \mathrm{~Hz}$, due to the coupling with $\mathrm{CH}$, while the protons of $\mathrm{NCH}_{2}$ respectively gave two dd at 3.43 and $3.74 \mathrm{ppm}$ $\left(J_{\mathrm{AB}}=11.6, J_{\mathrm{AX}}=2.1\right.$ and $\left.J_{\mathrm{BX}}=8.5 \mathrm{~Hz}\right)$. The preservation of a secondary hydroxyl is confirmed by a doublet at $5.19 \mathrm{ppm}$ in ${ }^{1} \mathrm{H}$ NMR spectrum, also by an absorption band at $3384 \mathrm{~cm}^{-1}$ in the IR spectrum. The direction of intramolecular cyclization can be estimated from the analysis of aromatic part of ${ }^{1} \mathrm{H}$ NMR spectrum. A sharp singlet at $7.19 \mathrm{ppm}$ is assigned to four protons of $p$ substituted phenylene, as is in accordance with structure 4, but not two protons as could be expected in the case of structure 5 . Moreover, the substitution of 1- $\mathrm{H}$ in naphthalene moiety can be clearly confirmed from the data of the appropriate part of ${ }^{1} \mathrm{H}$ NMR data (Figure 1). The resonance of $3-\mathrm{H}$ in compounds $\mathbf{2}$ and $\mathbf{3}$ gives rise to doublet of doublets due to its vicinal coupling to the 4-H $(J=9.0$ and 9.2, respectively) and coupling to $1-\mathrm{H}(J=2.4$ and 2.3). In a cyclization product the corresponding proton gives only a doublet $(J=9.0)$ because of missing of a meta-proton, the fact obvious for the structure 4. From all this we can conclude unambiguously, that cyclization occurs at 1-position of the naphthalene ring to give one of the presumable bifunctional compounds - 4,4`-(1,4-phenylene)di(1,2,3,4-tetrahydrobenzo[f]quinolin2-ol) (4).

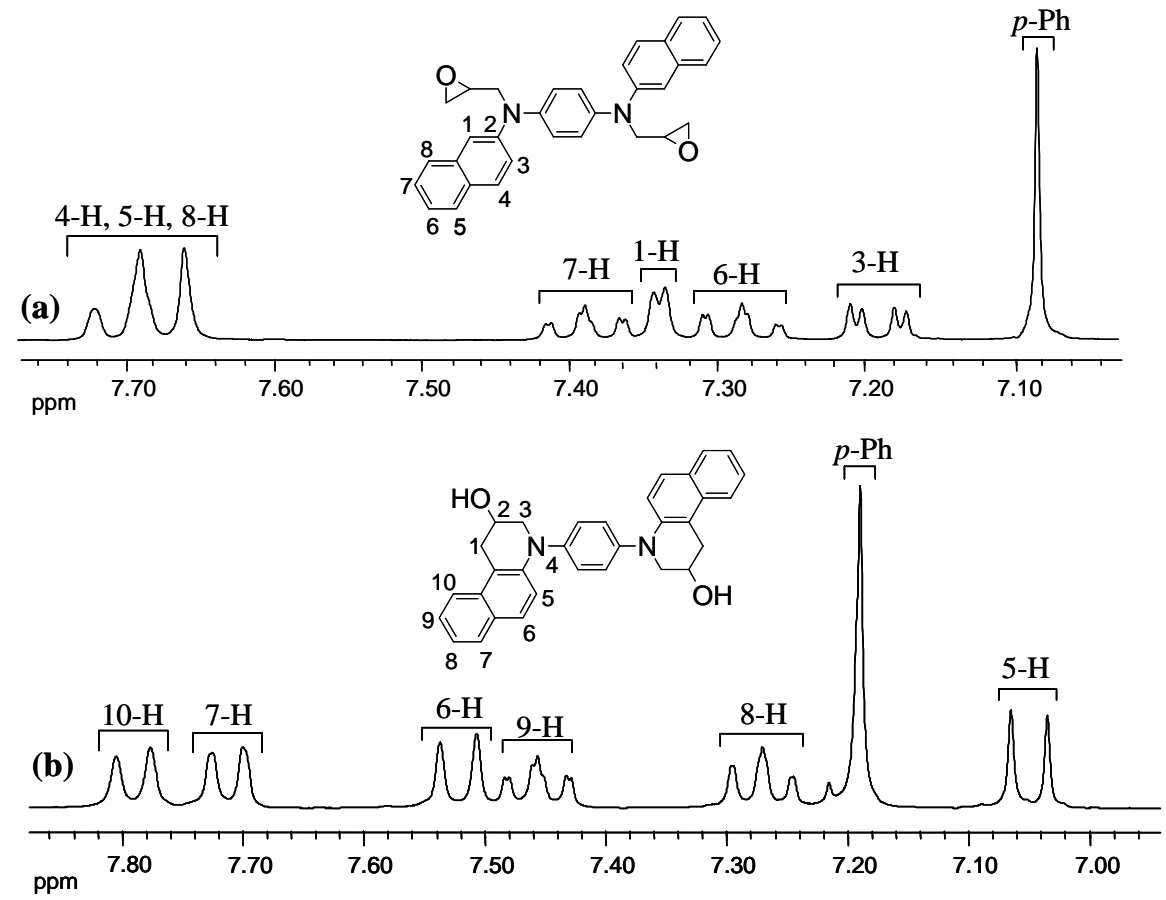

Figure 1. (a) Aromatic part of the ${ }^{1} \mathrm{H}$ NMR spectrum of $2\left(300 \mathrm{MHz}, \mathrm{CDCl}_{3}\right)$, (b) aromatic part of the ${ }^{1} \mathrm{H}$ NMR spectrum of $\mathbf{4}$ (300 MHz, DMSO- $\left.d_{6}\right)$. 
Additionally, the structure of $\mathbf{4}$ was confirmed by further acetylation it with acetic anhydride to give 6 .

It should be noticed, that the same bifunctional compound 4 is formed directly from 1, being refluxed in the excess of epichlorohydrin and acetic acid, but with a very low 9\% yield, compared to $45 \%$ for the proposed method.

\section{Conclusions}

In conclusion, intramolecular cyclization of $N, N{ }^{`}$-di(3-chloro-2-hydroxypropyl)- $N, N N^{`}$-di(2naphthyl)-1,4-diaminobenzene gives bifunctional 1,2,3,4-tetrahydro-benzo[f]quinoline derivative - 4,4 -(1,4-phenylene)di(1,2,3,4-tetrahydrobenzo[f]quinolin-2-ol).

\section{Experimental Section}

General Procedures. The NMR spectra were taken on a Varian Unity Inova spectrometer (300 $\mathrm{MHz}$ for ${ }^{1} \mathrm{H}$ and $75 \mathrm{~Hz}$ for ${ }^{13} \mathrm{C}$ ). The IR spectra were taken for samples in $\mathrm{KBr}$ pellets on a Perkin Elmer Spectrum BX II FT-IR System spectrometer. Mass spectra were recorded on Waters (Micromass) 2Q 200. Melting points were determined in capillary tubes on capillary melting point apparatus MEL-TEMP. The course of the reactions was monitored by TLC on Silufol UV-254 plates (acetone/n-hexane: 7/18), which were developed with $\mathrm{I}_{2}$ or UV light. Silica gel (grade 62, 60-200 mesh, $150 \AA$, Aldrich) was used for column chromatography. Elemental analyses were performed with an Exeter Analytical CE-440 Elemental Analyzer; their results agreed satisfactorily with the calculated values.

$N, N^{\prime}$-Di(2-naphthyl)- $N, N^{\prime}$-di(2-oxiranylmethyl)-1,4-diaminobenzene (2). A mixture of $N, N^{\prime}$ di(2-naphthyl)-1,4-diaminobenzene (1) (27 g, $0.08 \mathrm{~mol})$ and epichlorohydrin (125 mL, $1.6 \mathrm{~mol})$ was stirred vigorously for $20 \mathrm{~h}$ at $25-30{ }^{\circ} \mathrm{C} .85 \%$ powdered $\mathrm{KOH}(124 \mathrm{~g}, 1.88 \mathrm{~mol})$ and anhydrous $\mathrm{Na}_{2} \mathrm{SO}_{4}(43 \mathrm{~g}, 0.3 \mathrm{~mol}$ ) were added in 10 equal portions every 30 min with prior cooling of the reaction mixture to $30{ }^{\circ} \mathrm{C}$. Then the reaction mixture was extracted with ethyl acetate. The organic layer was dried $\left(\mathrm{MgSO}_{4}\right)$ and filtered. Ethyl acetate and excess of epichlorohydrin were removed under vacuum and the residue was dissolved in acetone. The crystals formed upon standing at $-5{ }^{\circ} \mathrm{C}$ temperature over the night. The crystals were filtered off, washed with 2-propanol and recrystallized from acetone to yield compound 2 (22 g, 62\%), mp 118-119.5 ${ }^{\circ} \mathrm{C}$. IR ( $\left.\mathrm{KBr}, \mathrm{cm}^{-1}\right) 3046\left(\mathrm{CH}_{\text {arom }}\right), 2991,2917\left(\mathrm{CH}_{\text {aliph }}\right), 1625,1596,1573(\mathrm{C}=\mathrm{C})$, 1222, 1185, 1144 (C-N), 913, 848, 833 ( $\mathrm{CH}=\mathrm{CH}$ of 1,4-di- and 1,2,4-trisubstituted benzenes), 833, 825 (epoxy ring), 747 ( $\mathrm{CH}=\mathrm{CH}$ of 1 ,2-disubstituted benzenes) $\mathrm{cm}^{-1}$; ${ }^{1} \mathrm{H}$ NMR (300 MHz, $\left.\mathrm{CDCl}_{3}, \mathrm{ppm}\right) \delta 7.74-7.64$ (6H, m, 4-H, 5-H and 8- $\mathrm{H}$ of naphthalene), 7.40, 7.38 (2H, two dd, $J=$ 7.8, 8.6, $1.2 \mathrm{~Hz}, 7-\mathrm{H}$ of naphthalene), 7.34 (2H, d, $J=2.4 \mathrm{~Hz}, 1-\mathrm{H}$ of naphthalene), 7.30, 7.27 
(2H, two dd, $J=7.8,7.8,1.0 \mathrm{~Hz}, 6-\mathrm{H}$ of naphthalene), 7.19 (2H, dd, $J=9.0,2.4 \mathrm{~Hz}, 3-\mathrm{H}$ of naphthalene), 7.09 (4H, s, $p-\mathrm{Ph}), 4.06\left(2 \mathrm{H}, \mathrm{dd}, J_{\mathrm{AB}}=15.7 \mathrm{~Hz}, J_{\mathrm{AX}}=3.6 \mathrm{~Hz}, \mathrm{H}_{\mathrm{A}}\right.$ from $\left.\mathrm{NC}_{2} \mathrm{CH}\right)$, $3.93\left(2 \mathrm{H}, \mathrm{dd}, J_{\mathrm{AB}}=15.7 \mathrm{~Hz}, J_{\mathrm{BX}}=4.0 \mathrm{~Hz}, \mathrm{H}_{\mathrm{B}}\right.$ from $\left.\mathrm{NC}_{2} \mathrm{CH}\right), 3.33-3.26(2 \mathrm{H}, \mathrm{m}, \mathrm{CH}), 2.83-$ $2.78\left(2 \mathrm{H}, \mathrm{m}, \mathrm{H}_{\mathrm{A}}\right.$, of $\mathrm{CH}_{2}$ from epoxy gr.), $2.61\left(2 \mathrm{H}, \mathrm{dd}, J_{\mathrm{A}^{\prime} \mathrm{B}}{ }^{\prime}=4.9 \mathrm{~Hz}, J_{\mathrm{B}}{ }^{\prime}{ }^{\prime}=2.7 \mathrm{~Hz}, \mathrm{H}_{\mathrm{B}}\right.$, of $\mathrm{CH}_{2}$ from epoxy gr.); ${ }^{13} \mathrm{C}$ NMR (75 $\left.\mathrm{MHz} \mathrm{CDCl}_{3}, \mathrm{ppm}\right) \delta 145.67,142.96,134.64,128.88,127.51$, 126.69, 126.35, 123.92, 126.65, 121.13, 113.81, 99.93, 54.24, 50.35, 46.05; MS (ESI) m/z 473 $\left([\mathrm{M}+\mathrm{H}]^{+}, 100 \%\right)$; Anal. Calcd for $\mathrm{C}_{32} \mathrm{H}_{28} \mathrm{~N}_{2} \mathrm{O}_{2}$ : C, 81.33; H, 5.97; N, 5.93. Found: C, 81.46; H, $5.84 ; \mathrm{N}, 6.17$.

$N, N^{\prime}$-Di(3-chloro-2-hydroxypropyl)- $N, N^{\prime}$-di(2-naphthyl)-1,4-diaminobenzene (3). 2 (5 g, $0.01 \mathrm{~mol})$ was dissolved in dioxane $(13 \mathrm{~mL})$ and concentrated $\mathrm{HCl}(2 \mathrm{~mL})$ was added dropwise. The reaction mixture was stirred at room temperature for $2.5 \mathrm{~h}$. After termination of the reaction, the reaction mixture was treated with ethyl acetate and washed with distilled water until the wash water was neutral. The organic layer was dried $\left(\mathrm{MgSO}_{4}\right)$, filtered and the solvents were removed. The residue was purified by column chromatography (acetone/n-hexane: 1/4) to afford 3 (4 g, 69 \%); IR ( $\left.\mathrm{KBr}, \mathrm{cm}^{-1}\right)$ 3365, $3053\left(\mathrm{CH}_{\text {arom }}\right)$, 2951, $2867\left(\mathrm{CH}_{\text {aliph }}\right), 1627,1596(\mathrm{C}=\mathrm{C}), 1216,1177$, 1146 (C-N), 907, 883, $834(\mathrm{CH}=\mathrm{CH}$ of 1,4-di- and 1,2,4-trisubstituted benzenes), 747 ( $\mathrm{CH}=\mathrm{CH}$ of 1,2-disubstituted benzenes); ${ }^{1} \mathrm{H}$ NMR (300 MHz, DMSO- $\left.d_{6}, \mathrm{ppm}\right) \delta 7.81-7.36(10 \mathrm{H}, \mathrm{m}, \mathrm{Ar}$ ), 7.29, 7.26 (2H, two dd, $J=7.8,7.8,1.2 \mathrm{~Hz}, 6-\mathrm{H}$ of naphthalene), 7.20 (2H, dd, $J=9.2,2.3 \mathrm{~Hz}$, 3-H of naphthalene), 7.16 (4H, s, p-Ph), 4.10-3.64 (12H, m, Aliph); ${ }^{13} \mathrm{C}$ NMR (75 MHz, DMSO$d_{6}$, ppm) $\delta 145.64,142.57,134.26,128.41,128.05,127.24,126.34,126.16,123.95,123.16$, 120.93, 112.85, 67.55, 55.59, 48.23; MS (APCI) m/z 545 ([M+H] $\left.]^{+}, 100 \%\right)$; Anal. Calcd for $\mathrm{C}_{32} \mathrm{H}_{30} \mathrm{Cl}_{2} \mathrm{~N}_{2} \mathrm{O}_{2}$ : C, 70.46; H, 5.54; Cl, 13.00; N, 5.14. Found: C, 70.34, H, 5.48, Cl, 13.08, N, 4.98. 4

\section{4,4'-(1,4-Phenylen)di(1,2,3,4-tetrahydrobenzo[f]quinolin-2-ol) (4).}

A) 3 (4.6 g, $8 \mathrm{mmol}$ ) was refluxed under the argon in 1-hexanol (15 mL) for $7 \mathrm{~h}$. After the reaction was completed, the solvent was removed by distillation, the obtained residue was dissolved in the mixture of ethyl acetate and THF, and the solution was worked up with $15 \%$ $\mathrm{NaHCO}_{3}$. The organic layer was washed with water until neutral, dried $\left(\mathrm{MgSO}_{4}\right)$ and filtered. Then the solvents were removed and the crystalline material was obtained. The crystals were filtered off, washed with 2-propanol and recrystallized from dioxane to obtain 4 (1.5 g, 38 \%), mp 266-268 ${ }^{\circ} \mathrm{C}$; IR (KBr, cm $\left.{ }^{-1}\right) 3384(\mathrm{OH}), 3038$ ( $\left.\mathrm{CH}_{\text {arom }}\right)$, 2946, 2914, $2841\left(\mathrm{CH}_{\text {aliph }}\right), 1620$, 1597, 1573 (C=C), 1194, 1147, $1129(\mathrm{C}-\mathrm{N}), 854,837$ ( $\mathrm{CH}=\mathrm{CH}$ of 1,4-disubstituted benzene), 791, 765 (naphthalene), 745 ( $\mathrm{CH}=\mathrm{CH}$ of 1,2-disubstituted benzenes); ${ }^{1} \mathrm{H}$ NMR (300 MHz, DMSO-d $d_{6}$ ppm) $\delta 7.79$ (2H, br d, $J=8.4 \mathrm{~Hz}, 10-\mathrm{H}$ of Ht), 7.71 (2H, br d, $J=7.5 \mathrm{~Hz}, 7-\mathrm{H}$ of Ht), 7.52 (2H, d, $J=9.0 \mathrm{~Hz}, 6-\mathrm{H}$ of Ht), 7.47, 7.45 (2H, two dd, $J=7.5,8.4,1.2 \mathrm{~Hz}, 9-\mathrm{H}$ of Ht), 7.28, 7.26 (2H, two dd, $J=7.5,7.5,0.5 \mathrm{~Hz}, 8-\mathrm{H}$ of Ht), 7.19 (4H, s, p-Ph), 7.05 (2H, d, $J=9.0 \mathrm{~Hz}, 5-$ $\mathrm{H}$ of $\mathrm{Ht}), 5.19(2 \mathrm{H}, \mathrm{d}, J=4.2 \mathrm{~Hz}, \mathrm{OH}), 4.27-4.15(2 \mathrm{H}, \mathrm{m}, \mathrm{CH}), 3.74\left(2 \mathrm{H}, \mathrm{dd}, J_{\mathrm{AB}}=11.6 \mathrm{~Hz}\right.$, $J_{\mathrm{AX}}=2.1 \mathrm{~Hz}, \mathrm{H}_{\mathrm{A}}$ from $\left.\mathrm{NCH}_{2}\right), 3.43\left(2 \mathrm{H}, \mathrm{dd}, J_{\mathrm{AB}}=11.6 \mathrm{~Hz}, J_{\mathrm{BX}}=8.5 \mathrm{~Hz}, \mathrm{H}_{\mathrm{B}}\right.$ from $\left.\mathrm{NCH}_{2}\right), 3.34$ $\left(2 \mathrm{H}\right.$, dd, $J_{\mathrm{A}^{\prime} \mathrm{B}}{ }^{\prime}=16.6 \mathrm{~Hz}, J_{\mathrm{A}^{\prime} \mathrm{X}^{\prime}}=5.4 \mathrm{~Hz}, \mathrm{H}_{\mathrm{A}^{\prime}}$ from $\left.\mathrm{C}_{2} \mathrm{CH}\right), 2.91\left(2 \mathrm{H}, \mathrm{dd}, J_{\mathrm{A}^{\prime} \mathrm{B}^{\prime}}=16.6 \mathrm{~Hz}, J_{\mathrm{B}^{\prime} \mathrm{X}^{\prime}}=\right.$ $7.4 \mathrm{~Hz}, \mathrm{H}_{\mathrm{B}}$, from $\mathrm{CH}_{2} \mathrm{CH}$ ); ${ }^{13} \mathrm{C}$ NMR (75 MHz, DMSO-d $\left.\mathrm{d}_{6}, \mathrm{ppm}\right) \delta 143.71,140.45,133.18$, 
128.10, 127.99, 126.44, 126.35, 124.66, 122.48, 121.54, 118.83, 114.46, 62.44, 56.80, 32.67; MS (ESI) $\mathrm{m} / \mathrm{z} 473\left([\mathrm{M}+1]^{+}, 100 \%\right)$. Anal. Calcd for $\mathrm{C}_{32} \mathrm{H}_{28} \mathrm{~N}_{2} \mathrm{O}_{2}$ : C, 81.33; H, 5.97; N, 5.93. Found: C, 81.26; H, 6.05; N, 5.78 .

B) 3 (4.5 g, $8 \mathrm{mmol})$ was heated at $156-157^{\circ} \mathrm{C}$ under the argon in 1,2-dichlorobenzene (20 mL) for 2,5 h. After the reaction was completed, the solvent was removed by distillation, the obtained residue was dissolved in chloroform and the solution was worked up with $15 \% \mathrm{NaHCO}_{3}$. The organic layer was washed with water until neutral, dried $\left(\mathrm{MgSO}_{4}\right)$ and filtered. Then the solvents were removed and methanol $(10 \mathrm{~mL})$ were added. The crystals formed over the night at $-5{ }^{\circ} \mathrm{C}$ temperature. The crystals were filtered off, washed with 2-propanol to yield 4 (1.8 g, 45\%).

C) 1 (3.6 g, $10 \mathrm{mmol})$ was refluxed in epichlorohydrin ( $16 \mathrm{~mL}, 0.9 \mathrm{~mol})$ and acetic acid $(2 \mathrm{~mL})$ for $23 \mathrm{~h}$. The reaction mixture was stored at room temperature and after 2 days crystallized. The crystals were filtered off, washed with water and diethyl ether to yield 4 (0.5 g, 9\%), mp 266-268 ${ }^{\circ} \mathrm{C}$. The analytical data is in accordance with that from A.

4,4'-(1,4-Phenylen)di(2-acetyl-1,2,3,4-tetrahydrobenzo[f]quinoline) (6). 4 (2 g, 4 mmol) was dissolved in acetic anhydride $(20 \mathrm{~mL})$ and the mixture was heated at $100{ }^{\circ} \mathrm{C}$ for $4 \mathrm{~h}$. After termination of the reaction, upon cooling a crystalline product formed. The crystals were filtered off, washed with water until neutral, then with diethyl ether and recrystallized from THF/dioxane: 1/6 to yield compound 6 (1.3 g, $53 \%$, mp 263-265.5 ${ }^{\circ} \mathrm{C}$; IR $\left(\mathrm{KBr}, \mathrm{cm}^{-1}\right)$ 3446, $3038\left(\mathrm{CH}_{\text {arom }}\right), 2954,2930,2882,2851\left(\mathrm{CH}_{\text {aliph }}\right), 1733$ (C=O), 1619, 1598, $1574(\mathrm{C}=\mathrm{C}), 1191$, 1115 (C-N), 874, 841 ( $\mathrm{CH}=\mathrm{CH}$ of 1,4-disubstituted benzene), 798, 774 (naphthalene), 751 ( $\mathrm{CH}=\mathrm{CH}$ of 1,2-disubstituted benzenes); ${ }^{1} \mathrm{H}$ NMR (300 MHz, $\left.\mathrm{CDCl}_{3}, \mathrm{ppm}\right) \delta 7.77$ (2H, dd, $J=$ 8.4, $0.8 \mathrm{~Hz}, 10-\mathrm{H}$ of Ht), 7.72 (2H, dd, $J=8.1,1.2 \mathrm{~Hz}, 7-\mathrm{H}$ of Ht), $7.53(2 \mathrm{H}, \mathrm{d}, J=9.0 \mathrm{~Hz}, 6-\mathrm{H}$ of $\mathrm{Ht}$ ), 7.49, 7.47 (2H, two dd, $J=8.2,8.4,1.2 \mathrm{~Hz}, 9-\mathrm{H}$ of $\mathrm{Ht}$ ), 7.33, 7.30 (2H, two dd, $J=8.2$, 8.1, $0.8 \mathrm{~Hz}, 8-\mathrm{H}$ of Ht), 7.14 (4H, s, $p-\mathrm{Ph}), 7.12$ (2H, d, $J=9.0 \mathrm{~Hz}, 5-\mathrm{H}$ of Ht), 5.50-5.42 (2H, m, $\mathrm{CH})$, 3.92-3.79 $\left(4 \mathrm{H}, \mathrm{m}, \mathrm{NCH}_{2}\right), 3.47\left(2 \mathrm{H}, \mathrm{dd}, J_{\mathrm{AB}}=17.0 \mathrm{~Hz}, J_{\mathrm{AX}}=5.6 \mathrm{~Hz}, \mathrm{H}_{\mathrm{A}}\right.$ from $\left.\mathrm{C}_{2} \mathrm{CH}\right)$, $3.23\left(2 \mathrm{H}, \mathrm{dd}, J_{\mathrm{AB}}=17.0 \mathrm{~Hz}, J_{\mathrm{BX}}=4.7 \mathrm{~Hz}, \mathrm{H}_{\mathrm{B}}\right.$ from $\left.\mathrm{C}_{2} \mathrm{CH}\right), 1.95\left(6 \mathrm{H}, \mathrm{s}, \mathrm{CH}_{3}\right) ; \mathrm{MS}$ (APCI) $\mathrm{m} / \mathrm{z}$ 557 ([M+H] $\left.]^{+}, 100 \%\right)$; Anal. Calcd. for $\mathrm{C}_{36} \mathrm{H}_{32} \mathrm{~N}_{2} \mathrm{O}_{4}$ : C, 77.68; H, 5.79; N, 5.03. Found: C, 77.53; H, 5.87; N, 4.95.

\section{Acknowledgements}

This work was financially supported by grants from the Lithuanian Science and Studies Foundation.

\section{References}

1. Perry, N. B.; Blunt, J. W.; Mc Combs, J. D.; Munro, M. H. G. J. Org. Chem. 1986, 51, 5476.

2. Perry, N. B.; Blunt, J. W.; Munro, M. H. G. Tetrahedron 1988, 44, 1727. 
3. Nishiyama, S.; Cheng, J. F.; Tao, X. L.; Yamamura, S. Tetrahedron Lett. 1991, 32, 4151.

4. Kita, Y.; Tohma, H.; Inagaki, M.; Hatanaka, K.; Yakura, T. J. Am. Chem. Soc. 1992, 114, 2175.

5. White, J. D.; Yager, K. M.; Yakura, T. J. Am. Chem. Soc. 1994, 116, 1831.

6. Kokwaro, G. O.; Taylor, G. Drug Chem. Toxicol. 1990, 13, 347.

7. Francis, C. L.; Ward, A. D. Aust. J. Chem. 1994, 47, 2109.

8. Omura, S.; Nakagawa, A. Tetrahedron Lett. 1981, 22, 2199.

9. Tsushima, K.; Osumi, T.; Matsuo, N.; Itaya, N. Agric. Biol. Chem. 1989, 53, 2529.

10. Nishiyama, T.; Hashiguchi, Y.; Sakata, T.; Sakaguchi, T. Polymer Degradation and Stability 2003, 79, 225.

11. Shikhaliev, K. S.; Shmyreva, Z.; Gurova, E. M. Izv. Vyssh. Uchebn. Zaved., Khim. Khim. Technol. 1989, 32, 85; Chem. Abstr. 1990, 112, 216659a.

12. Rechardt, C.; Harms, K.; Kinzel, M.; Schafer, G.; Stein, J.; Wocadlo, S. Liebigs. Ann. 1995, 317.

13. Getautis, V.; Stanisauskaite, A.; Malinauskas, T.; Stumbraite, J.; Gaidelis, V.; Jankauskas, V. Monatsh. Chem. 2006, 137, 1401.

14. Getautis, V; Stumbraite, J.; Gaidelis, V.; Jankauskas, V.; Kliucius, A.; Paulauskas, V. Synth. Met. 2007, 157, 35.

15. Katricky, A. R.; Rachwal, S.; Rachwal, B. Tetrahedron 1996, 52, 15031.

16. Barvainiene, B.; Stanisauskaite, A.; Getautis, V. Khim. Geterotsikl. Soedin. 2006, 1, 138.

17. Vorozhtsov, N. N.; Kutkevichus, S. I. Khim. Geterotsikl. Soedin. 1965, 3, 374.

18. Getautis, V.; Stanisauskaite, A.; Malinauskas, T.; Stumbraite, J.; Gaidelis, V.; Jankauskas, V. Monatsh. Chem. 2006, 137, 1401.

19. Kutkevichus, S. I.; Vorozhtsov, N. N. Khim. Geterotsikl. Soedin. 1965, 4, 549.

20. Getautis, V.; Stanisauskaite, A.; Degutyte, R.; Stumbraite, J. Monatsh. Chem. 2007, 138, 1293. 